\title{
Investigation of Electrocardiography Changes and, Specifically, Changes in the TpTe Interval and TpTe/QT Ratio in Patients Presenting with Electrical Injuries
}

\author{
Yahya Kemal Günaydın', Can Gökay Yıldız², Ahmet Çağlar², Nazire Belgin Akıllı², Ramazan Köylü², Başar Cander³ \\ 'Department of Emergency Medicine, Ankara Training and Research Hospital, Ankara, Turkey \\ 2Department of Emergency Medicine, Konya Training and Research Hospital, Konya, Turkey \\ ${ }^{3}$ Department of Emergency Medicine, Necmettin Erbakan University School of Medicine, Konya, Turkey
}

\begin{abstract}
Aim: The purpose of this study was to examine changes in cardiac monitoring, electrocardiography (ECG), or cardiac enzymes and, specifically, changes in the TpTe interval and TpTe/QT ratio in patients who presented with electrical injuries.

Materials and Methods: All patients aged over 18 years who had visited the Emergency Medicine Clinic between January 2011 and January 2014 because of electrical injuries and who were monitored for more than $24 \mathrm{~h}$ were included.

Results: Seventy patients were included in the trial. ECG changes were present in 19 patients $(27.1 \%)$ at various time points $\left(0^{\text {th }}, 6^{\text {th }}, 12^{\text {th }}\right.$, and $24^{\text {th }}$ hour). The TpTe intervals of the patients at the time points were 64.5 (IQR: 21.25), 65 (IQR: 21.5), 64 (IQR: 20), and 64 (IQR: 20) ms, respectively, which were within the normal range. Although a statistical difference was present $(p=0.033)$, superior analyses showed no significant difference among the groups. The TpTe/QT ratios of the patients were $0.18(0.07), 0.18(0.05), 0.18(0.06), 0.18(0.05)$, respectively, which were within the normal range $(p=0.105)$. We compared the TpTe intervals and TpTe/QT ratios of patients with and without ECG changes and found that no statistically significant difference was present at all time points. Besides this, no difference in the TpTe intervals and TpTe/QT ratios was identified between the groups with elevated and non-elevated troponin levels.

Conclusion: The use of TpTe intervals and TpTe/QT ratios may not be the correct approach for predicting potential rhythm disorders in electrical injuries. In addition, there is no association of the TpTe interval or the TpTe/QT ratio with ECG changes or troponin elevation caused by electrical injuries.

Keywords: Electrical injuries, electrocardiography, TpTe interval
\end{abstract}

\section{Introduction}

Electrical injuries (Els) are associated with high morbidity and mortality and are a type of trauma that puts all age groups at risk (1). In the USA, more than 500 deaths are attributed to Els annually (2). Els can cause cardiac arrest, myocardial and valvular ruptures, structural changes in the coronary arteries, pericardial effusion, and various electrocardiography (ECG) changes. In most patients, at the very least, temporary ECG changes can be observed $(3,4)$. The purpose of our study was to investigate the epidemiologic characteristics of Els, cardiac monitoring, ECG reports, and cardiac enzyme changes and, specifically, the TpTe and QT intervals and TpTe/QT ratio that develop in patients presenting with Els.

\section{Materials and Methods}

\section{Study population and study protocol}

All patients who had visited the Emergency Medicine Clinic of Konya Training and Research Hospital between January 2011 and January 2014 because of Els, who were monitored for more than $24 \mathrm{~h}$, and who were over 18 years of age were included. This retrospective study was conducted by reviewing patient files. The cases were reviewed with regard to gender, age, location of $\mathrm{El}$, course of $\mathrm{El}$, and cause (low voltage or high voltage). Further, changes in ECG and cardiac enzymes, specifically, TpTe and QT intervals and the $\mathrm{TpTe/QT}$ ratio, and their association with rhythm disorders were investigated".

Correspondence to: Yahya Kemal Günaydın e-mail: gsykg@yahoo.com 
The study protocol was approved by the Necmettin Erbakan University Faculty of the Medicine Ethics Committee and was conducted in accordance with the Declaration of Helsinki and Good Clinical Practice.

\section{Electrocardiography measurement}

The ECG records of the patients at baseline $(0 \mathrm{~h})$ and at 6,12 , and $24 \mathrm{~h}$ were evaluated. The Nihon Kohden ECG 1250 Cardiofax S (2009, Tokyo, Japan) device was used for recording ECGs. Records were obtained at a speed of $25 \mathrm{~mm} / \mathrm{s}$ and with an amplitude of $10 \mathrm{~mm} / \mathrm{mV}$. The ECG records were at 800-dpi resolution and were measured by two specialists uninformed about the patient's conditions and with the help of a computer. The PR interval was measured as the distance from the start of the $P$ wave to the start of the QRS complex (normal range of PR interval: $120-200 \mathrm{~ms}$ ). A prolonged QRS duration was defined as $\geq 120 \mathrm{~ms}$

The TpTe interval was measured in precordial derivations by the "tail method." According to this, the distance between the projection of the T-wave's peak point on the isoelectric line and the end of the T wave was measured (normal range of TpTe: $\leq 85 \mathrm{~ms}$ ) (5-7). The QT interval was measured as the distance between the start of the QRS complex and the end of the T wave (normal QT: 360-440 ms). In addition, in situations when the heart rate was not in a normal range, the corrected QT interval was calculated using Bazett's formula (710). This prevented abnormalities in the heart rate from affecting the $\mathrm{TpTe} / \mathrm{QT}$ ratio (10). The TpTe/QT ratio was calculated after the TpTe interval was measured (11).

\section{Statistical analysis}

Statistical analysis was performed using the Statistical Package for the Social Sciences (SPSS Inc.; Chicago, IL, USA) version 15.0 for Windows. Both visual (histogram and probability graphs) and analytical (Kolmogorov-Smirnov and Shapiro-Wilk tests) methods were used to determine if the data were normally distributed. Descriptive variables are expressed as the mean $\pm S D$ for data normally distributed and as the median and interquartile range (IQR) for variables not normally distributed. Clinical and laboratory characteristics were evaluated via the Mann-Whitney $U$ test for variables without normal distribution. For comparison of the differences among the groups, the Mann-Whitney $U$ test was used for quantitative variables and the chi-square test was used for categorical variables. Hourly differences in the ECG parameters were evaluated via repeated measures analysis of variance for normally distributed variables, whereas variables without normal distribution were evaluated via the Friedman test. When necessary, the Wilcoxon test with the Bonferroni correction was used to compare variables. A $p$ value of $<0.05$ was accepted as statistically significant with a $95 \%$ confidence interval.

\section{Results}

During the study period, 187 patients with Els visited our clinic. Out of these patients, 45 were excluded because they were under the age of 18 years. In addition, 72 patients were excluded because they were monitored for less than $24 \mathrm{~h}$. This left 70 patients who were included in the trial. The median age of the patients was 24 years (IQR: 22). The number of male patients was 55 (78.6\%). Twenty-three patients (32.9\%) were exposed to a high-voltage electrical current. When the Glasgow Coma Scores (GCSs) of the patients were
Table 1.24-h ECG analysis of patients

\begin{tabular}{|l|c|c|c|c|}
\hline & $\begin{array}{c}\text { At the } \\
\mathbf{0}^{\text {th }} \text { hour } \\
\text { Number } \\
\text { (n) (\%) }\end{array}$ & $\begin{array}{c}\text { At the } \\
\mathbf{6}^{\text {th }} \text { hour } \\
\text { Number } \\
\text { (n) (\%) }\end{array}$ & $\begin{array}{c}\text { At the } \\
\mathbf{1 2}^{\text {th }} \text { hour } \\
\text { Number } \\
\text { (n) (\%) }\end{array}$ & $\begin{array}{c}\text { At the } \\
\mathbf{2 4}^{\text {th }} \text { hour } \\
\text { Number } \\
\text { (n) (\%) }\end{array}$ \\
\hline NSR & $55(78.6)$ & $63(90)$ & $65(92.9)$ & $65(92.9)$ \\
\hline Sinus bradycardia & $2(2.9)$ & $3(4.3)$ & $1(1.4)$ & $2(2.9)$ \\
\hline Sinus tachycardia & $7(10)$ & $3(4.3)$ & $2(2.9)$ & $1(1.4)$ \\
\hline T-wave inversion & $1(1.4)$ & - & - & $1(1.4)$ \\
\hline ST segment elevation & $1(1.4)$ & - & - & - \\
\hline ST segment depression & $1(1.4)$ & - & $1(1.4)$ & - \\
\hline Sinus arrhythmia & $1(1.4)$ & - & - & - \\
\hline $1^{\text {st }}$ degree AV block & $1(1.4)$ & - & - & - \\
\hline Ventricular fibrillation & $1(1.4)$ & - & - & - \\
\hline Ventricular tachycardia & - & $1(1.4)$ & - & - \\
\hline Cardiac arrest & - & - & $1(1.4)$ & $1(1.4)$ \\
\hline Total & $70(100)$ & $70(100)$ & $70(100)$ & $70(100)$ \\
\hline EcG & - & & \\
\hline
\end{tabular}

ECG: electrocardiogram; NSR: normal sinus rhythm

reviewed on admission, 66 (94.3\%) had a GCS of 15, while the remaining 4 (5.7\%) had GCSs of 3, 6, 8, and 9. Eleven (15.7\%) patients had elevated cardiac injury marker levels (troponin $>0.2 \mathrm{ng} / \mathrm{mL}$ ), while four $(5.7 \%)$ had respiratory failure (need for endotracheal intubation and mechanic ventilation).

Electrocardiography changes were present in 19 (27.1\%) patients at various time points of the 24-hour ECG monitoring. The most common ECG change was identified as sinus tachycardia. Ventricular tachycardia (VT) and ventricular fibrillation (VF) occurred in one patient each. These patients were administered amiodarone and underwent electrical cardioversion, defibrillation, and cardiopulmonary resuscitation. Two (2.9\%) of our patients died, and 68 (97.1\%) were discharged from the hospital. The PR, QRS, QT, and TpTe intervals and the TpTe/QT ratio were evaluated at baseline and at 6, 12, and $24 \mathrm{~h}$. The QT intervals of the 70 patients were 370 (IQR: 40), 380 (IQR: 35), 380 (IQR: 43.5), and 382 (IQR: 36) $\mathrm{ms}$ at baseline and at 6, 12, and $24 \mathrm{~h}$, respectively, which were within normal ranges. No statistically significant difference was present $(p=0.059)$. The TpTe intervals of the 70 patients were 64.5 (IQR: 21.25), 65 (IQR: 21.5), 64 (IQR: 20), and 64 (IQR: 20) $\mathrm{ms}$ at baseline and at 6, 12, and $24 \mathrm{~h}$, respectively, which were within normal ranges. Although a statistically significant difference was apparent $(p=0.033)$, the superior analysis showed no significant difference. The TpTe/QT ratio of the 70 patients were 0.18 (0.07), 0.18 (0.05), $0.18(0.06)$, and $0.18(0.05)$ at baseline and at 6, 12, and $24 \mathrm{~h}$, respectively, which were within normal ranges. No statistically significant difference was shown $(p=0.105)$. The details of these differences are shown in Tables 1 and 2. In addition, we compared the TpTe, QT intervals, and the TpTe/QT ratios in patients with and without ECG changes. The ECG records at baseline and at 6, 12, and $24 \mathrm{~h}$ were evaluated individually. There was no statistically significant difference among the groups at all time points (Table 3).

We compared the ECG changes and troponin elevation in patients with high- and low- voltage Els. The median age of patients with high-voltage injuries was 28 years (IQR: 16), whereas that of 
Table 2. Analysis of the ECG findings of the patients

\begin{tabular}{|c|c|c|c|c|c|}
\hline \multirow[b]{2}{*}{ ECG } & \multicolumn{4}{|c|}{ Median value (IQR) } & \multirow[b]{2}{*}{$\mathbf{p}$} \\
\hline & At $0^{\text {th }}$ hour & At $6^{\text {th }}$ hour & At $12^{\text {th }}$ hour & At $24^{\text {th }}$ hour & \\
\hline PR interval (ms*) & $140(23)$ & $150(23)$ & $140(28)$ & $150(20)$ & 0.042 \\
\hline QRS distance (ms) & $85(20)$ & $92(20)$ & $90(19)$ & $90(20)$ & $0.019^{a}$ \\
\hline QT interval (ms) & $370(40)$ & $380(35)$ & $380(43.5)$ & $382(36)$ & 0.059 \\
\hline TpTe interval (ms) & $64.5(21.25)$ & $65(21.5)$ & $64(20)$ & $64(20)$ & 0.033 \\
\hline TpTe/QT & $0.18(0.07)$ & $0.18(0.05)$ & $0.18(0.06)$ & $0.18(0.05)$ & 0.105 \\
\hline
\end{tabular}

Table 3. Comparing the TpTe intervals and TpTe/QT ratios of patients with and without ECG changes

\begin{tabular}{|l|c|c|c|}
\hline & $\begin{array}{c}\text { Patients } \\
\text { with ECG } \\
\text { changes (n: 19) }\end{array}$ & $\begin{array}{c}\text { Patients } \\
\text { with no ECG } \\
\text { changes (n: 51) }\end{array}$ & p \\
\hline First TpTe interval & 71 (IQR: 27.5$)$ & 64.5 (IQR: 20) & 0.622 \\
\hline TpTe interval at the $6^{\text {th }}$ hour & 65 (IQR: 21.5$)$ & 67 (IQR: 22) & 0.973 \\
\hline TpTe interval at the $12^{\text {th }}$ hour & 63.5 (IQR: 20) & 64 (IQR: 21$)$ & 0.591 \\
\hline TpTe interval at the $24^{\text {th }}$ hour & 63.5 (IQR: 20) & 64 (IQR: 21$)$ & 0.591 \\
\hline First QT interval & 386 (IQR: 46.3) & 367 (IQR: 36) & 0.400 \\
\hline QT interval at the $6^{\text {th }}$ hour & 377 (IQR: 54.5) & 380 (IQR: 34) & 0.753 \\
\hline QT interval at the $12^{\text {th }}$ hour & 380 (IQR: 50) & 380 (IQR: 42) & 0.612 \\
\hline QT interval at the $24^{\text {th }}$ hour & 388 (IQR: 46.3) & 380 (IQR: 34) & 0.676 \\
\hline First TpTe/QT & 0.18 (IQR: 0.08$)$ & 0.18 (IQR: 0.06) & 0.843 \\
\hline TpTe/QT at the $6^{\text {th }}$ hour & 0.19 (IQR: 0.07$)$ & 0.18 (IQR: 0.05) & 0.946 \\
\hline TpTe/QT at the $12^{\text {th }}$ hour & 0.18 (IQR: 0.06) & 0.18 (IQR: 0.06) & 0.738 \\
\hline TpTe/QT at the $24^{\text {th }}$ hour & 0.17 (IQR: 0.05) & 0.18 (IQR: 0.05) & 0.618 \\
\hline Mann-Whitney U test, Interval: milliseconds. & & \\
\hline
\end{tabular}

patients with low-voltage injuries was 24 years (IQR: 22). No statistically significant difference in the ages of the patients in these two groups was shown $(p=0.05)$. When genders of the patients in these two groups were compared, 23 males and no females were present in the high-voltage group, while 32 males and 15 females were present in the low-voltage group. A statistically significant difference in gender was present between the groups $(p=0.001)$. High-voltage Els were more common in males. ECG changes were identified in $10 \%$ of high-voltage Els and $17.1 \%$ of low-voltage Els. In addition, troponin levels were elevated in $8.6 \%$ of high-voltage Els and in $7.1 \%$ of low-voltage Els. No statistically significant difference in ECG changes and troponin level elevation was shown between the two groups $(p=0.665$ and $p=0.095$, respectively) (Table 4).

The median age of patients with elevated troponin levels was 26.5 years (IQR: 23.25 ) and 26 years (IQR: 21 ) in patients without elevated troponin levels. In the group with elevated troponin levels, there were 11 males and no females, while in the group without elevated troponin levels, there were 44 males and 15 females. The age and gender was compared in patients with elevated troponin levels caused by Els and without elevated troponin levels, but no difference was seen ( $p=0.471$ and $p=0.105$, respectively). However,
Table 4. Comparison of the ECG changes and troponin elevations in patients with high- and low-voltage Els

\begin{tabular}{|c|c|c|c|}
\hline & $\begin{array}{l}\text { High-voltage } \\
\text { EI (n: 23) }\end{array}$ & $\begin{array}{l}\text { Lo- voltage } \\
\text { EI (n: 47) }\end{array}$ & $\mathbf{p}$ \\
\hline Age & 28 (IQR: 16) & 24 (IQR: 22) & 0.05 \\
\hline Gender & M: 23; F: 0 & M: 32; F: 15 & 0.001 \\
\hline ECG Changes & $7(10 \%)$ & $12(17.1 \%)$ & 0.665 \\
\hline \multirow[t]{2}{*}{ Troponin Elevation } & $6(8.6 \%)$ & $5(7.1 \%)$ & 0.095 \\
\hline & $\begin{array}{l}\text { Patients with } \\
\text { elevated } \\
\text { troponin } \\
\text { levels (n: } 11 \text { ) }\end{array}$ & \begin{tabular}{|} 
Patients without \\
elevated \\
troponin \\
levels (n:59)
\end{tabular} & \\
\hline Age & 26.5 (IQR: 23.25) & 26 (IQR: 21) & 0.471 \\
\hline Gender & M: 11;F:0 & M: 44; F: 15 & 0.105 \\
\hline ECG Changes & $7(10 \%)$ & $12(17.1 \%)$ & 0.007 \\
\hline First TpTe interval & 75.5 (IQR: 22.1) & 64 (IQR: 22) & 0.339 \\
\hline TpTe interval at the $6^{\text {th }}$ hour & 80.5 (IQR: 20.5) & 65 (IQR: 22) & 0.325 \\
\hline TpTe interval at the $12^{\text {th }}$ hour & 71 (IQR: 25) & 64 (IQR: 20) & 0.870 \\
\hline TpTe interval at the $24^{\text {th }}$ hour & 71 (IQR: 25) & 64 (IQR: 20) & 0.870 \\
\hline First QT interval & $389(41)$ & $370(42)$ & 0.428 \\
\hline QT interval at the $6^{\text {th }}$ hour & $382(28)$ & $380(37)$ & 0.701 \\
\hline QT interval at the $12^{\text {th }}$ hour & $380(31.8)$ & $380(42)$ & 0.561 \\
\hline QT interval at the $24^{\text {th }}$ hour & $386(10.5)$ & $380(40)$ & 0.884 \\
\hline First TpTe/QT & $0.185(0.05)$ & $0.170(0.07)$ & 0.501 \\
\hline TpTe/QT at the $6^{\text {th }}$ hour & $0.206(0.04)$ & $0.175(0.05)$ & 0.091 \\
\hline TpTe/QT at the $12^{\text {th }}$ hour & $0.191(0.06)$ & $0.180(0.06)$ & 0.980 \\
\hline TpTe/QT at the $24^{\text {th }}$ hour & $0.182(0.07)$ & $0.172(0.05)$ & 0.905 \\
\hline
\end{tabular}

when the ECG changes in the two groups were compared, it was seen that ECG changes were identified in $10 \%$ of the patients with elevated troponin levels and in $17.1 \%$ of the patients without elevated troponin levels. The difference was statistically significant $(p=0.007)$. In addition, no differences in TpTe, QT intervals, and TpTe/QT ratios were identified among patients in the group with elevated troponin levels and those in the group without elevated troponin levels (Table 4). 


\section{Discussion}

It is expressed that the degree of myocardial injury increases as the voltage gets higher (12). Asystole and VF are fatal cardiac problems caused by El, and besides these, ECG changes, such as sinus tachycardia, non-specific ST-T changes, heart blocks, QT elongation, supraventricular-ventricular arrhythmias, and atrial fibrillation, may also develop (13). Akkaş et al. (14) identified normal sinus rhythm in $76 \%$, sinus tachycardia in $9 \%$, sinus bradycardia in $3 \%$, ST-T changes in $4 \%$, and premature ventricular beats in $1 \%$ of the 120 patients with Els in their study, while cardiac enzymes were elevated in only $4 \%$ of the patients and acute coronary syndrome did not develop in any of the patients. In addition, eight patients in their study died due to cardiac problems that started at the time of El and one died of sepsis. In the patients that survived, no ECG changes that required medical or electrical treatment were observed. Arrowsmith et al. (15) stated that ECG changes were present in 3\% of the patients in their study. In the study conducted by Karadaş et al. (16), ECG abnormalities were identified in $29.3 \%$ of the patients. In our study, similar to medical literature, the results of the evaluations of the 24-hour ECG monitoring showed that ECG changes were present in 19 (27.1\%) of the patients at various time points. The most common ECG change was identified as sinus tachycardia. One of our patients died due to VF and one died due to VT within 6 hours. In addition, cardiac enzymes were high in $11(15.7 \%)$ of our patients.

Some authors recommend ECG monitoring after every EI $(3,12)$ because ECG changes have been identified in past studies, whereas others state that this is necessary only in selected cases (17). Teodoreanu et al. (18) stated that cardiac monitoring is indicated if cardiac arrest or loss of consciousness occurs, if the ECG is abnormal or if a dysrhythmia is present, if the patient has a history of cardiac disease or important cardiac risk factors before hospital admittance, and if the patient has severe injuries, chest pain, or hypoxia. In the present study, we also investigated the need for 24 -hour cardiac monitoring. Normal sinus rhythms were observed in $78.6 \%$ of patients at baseline, $90 \%$ at the $6^{\text {th }}$ hour, and $92 \%$ at the $12^{\text {th }}$ and $24^{\text {th }}$ hours. We observed that only two patients died in the first 6 hours because of cardiac arrest caused by VT or VF and that no other patient experienced serious rhythm disorders after 6 hours. We proposed that, when no ECG changes are present at baseline or in the first 6 hours, prolonged cardiac monitoring is unnecessary for these patients.

We aimed to report, for the first time, the measured TpTe interval and TpTe/QT ratio values as a new method for predicting rhythm disorders in Els. In past studies on the TpTe interval, it has been identified that the prolongation of the TpTe interval is a potential risk factor for the development of re-entry ventricular arrhythmias $(19,20)$. In addition, it has been observed that prolonged QT intervals increase the mortality risk in congenital or acquired long QT syndromes and in hypertrophic cardiomyopathy patients with troponin I mutations $(11,21)$. It has also been shown that they are associated with malignant arrhythmias in prolonged TpTe interval long QT syndrome, hypertrophic cardiomyopathy, Brugada syndrome, and AMI (11). Besides these, another important new parameter is the TpTe/QT ratio. In a study on animals such as cows and pigs, the ratio was measured to be between 0.17 and 0.23 (on average, 0.21 in healthy adults), and it has been reported to play an important role in the electrical stability of the myocardium. It is also very useful in counteracting the individual differences in the heart rate and QT interval (22). It has been stated that the TpTe interval and the new transmyocardial repolarization marker the TpTe/QT ratio are superior to the QT interval in predicting arrhythmias (23). In their study including 353 cardiac arrest cases, Panikkath et al. (7) reported that prolonged TpTe $(\geq 85$ $\mathrm{ms}$ ) and high TpTe/QT ratios are strongly associated with cardiac arrest. Lubinski et al. (24) reported that prolonged TpTe intervals and high TpTe/QT ratios are associated with VT in coronary artery disease patients. Because the TpTe interval and TpTe/QT ratio are important in cardiac rhythm disorders, we investigated if Els cause prolonged TpTe intervals and high TpTe/QT ratios in our study. However, we were unable to identify any prolongation in the TpTe interval or increase in the TpTe/QT ratio in Els. In addition, we were unable to identify an association of the TpTe interval or the TpTe/QT ratio with ECG changes in patients with Els.

It is known from the medical literature that ECG changes occur with both high-and low-voltage currents (25). In their study, Karadaş et al. (16) identified ECG changes in only $8.9 \%$ of low-voltage Els. Rai et al. (26) identified ECG changes secondary to shock or arrhythmia in seven of 58 patients with high-voltage Els. They also reported that fatal arrest developed in two patients exposed to a high-voltage current in the same study. In our study, there was no difference in ECG changes and there were no troponin level increases between highand low-voltage Els.

Akkaş et al. (14) reported that troponin levels were elevated in only $4 \%$ of their patients. Jensen (3) was also unable to detect a significant elevation in troponin levels.

In our study, troponin levels were elevated in $15.7 \%$ of the patients. However, in our patient group with elevated troponin levels, the number of patients with ECG changes identified was fewer than expected. Thus, we must be careful in using elevation in troponin levels for predicting ECG changes in patients with Els.

\section{Study limitations}

The major limitation of this study is the low number of patients, particularly of patients with ECG changes. Conducting this study in a larger patient group that includes patients with more severe arrhythmias might provide an opportunity to gather more definite results.

\section{Conclusion}

Using the TpTe interval and TpTe/QT ratio in predicting potential rhythm disorders that develop in Els may not be an appropriate approach. In addition, there is no association of the TpTe interval or the TpTe/QT ratio with ECG changes or troponin level increase because of Els. It is unnecessary to continue cardiac monitoring for longer periods of time if no ECG changes are present at baseline or have not developed in the first 6 hours.

Ethics Committee Approval: Ethics committee approval was received for this study from the ethics committee of Necmettin Erbakan University Faculty of Medicine.

Informed Consent: Written informed consent wasn't obtained from patients who participated in this study because our study is a retrospective study and the data obtained by screening of the patient files.

Peer-review: Externally peer-reviewed.

Conflict of Interest: No conflict of interest was declared by the authors. 
Financial Disclosure: The authors declared that this study has received no financial support.

\section{References}

1. Koumbourlis AC. Electrical injuries. Crit Care Med 2002; 30:424-30. [CrossRef]

2. Kisner S, Casini V. Epidemiology of electrocution fatalities. In: Worker Deaths by Electrocution: A Summary of NIOSH Surveillance and Investigative Findings. Publication; Washington, DC: (NIOSH); 1998. p. 9-19.

3. Jensen PJ, Thomsen PE, Bagger JP, Norgaard A, Baandrup U. Electrical injury causing ventricular arrhythmias. Br Heart J 1987; 57: 279-83. [CrossRef]

4. Burda CD. Electrocardiographic changes in lightning stroke. Am Heart J 1966; 72: 521-4. [CrossRef]

5. Salles GF, Cardoso CRL, Leocardio SM, Muxfeldt ES. Recent ventricular repolarization markers in resistant hypertension: Are they different from the traditional QT interval? Am J Hypertens 2008; 21: 47-53. [CrossRef]

6. Erikssen G, Liestøl K, Gullestad L, Haugaa KH, Bendz B, Amlie JP. The terminal part of the QT interval (T peak to T end): a predictor of mortality after acute myocardial infarction. Ann Noninvasive Electrocardiol 2012; 17: 85-94. [CrossRef]

7. Panikkath R, Reinier K, Uy-Evanado A, Teodorescu C, Hattenhauer J, Mariani $R$, et al. Prolonged Tpeak-to-tend interval on the resting ECG is associated with increased risk of sudden cardiac death. Circ Arrhythm Electrophysiol 2011; 4: 441-7. [CrossRef]

8. Antzelevitch C, Viskin S, Shimizu W, Yan GX, Kowey P, Zhang L, et al. Does Tpeak-Tend provide an index of transmural dispersion of repolarization? Heart Rhythm 2007; 4: 1114-6. [CrossRef]

9. Perkiomaki JS, Koistinen MJ, Yli-Mayry S, Huikuri HV. Dispersion of QT interval in patients with and without susceptibility to ventricular tachyarrhythmias after previous myocardial infarction. J Am Coll Cardiol 1995; 26: 174-9. [CrossRef]

10. Bazett HC. An analysis of the time-relations of electrocardiograms. Heart 1920; 7: 353-7.

11. Shimizu M, Ino H, Okeie K, Yamaguchi M, Nagata M, Hayashi K, et al. T-peak to T-end interval may be a better predictor of high-risk patients with hypertrophic cardiomyopathy associated with a cardiac troponin I mutation than QT dispersion. Clin Cardiol 2002; 25: 335-9. [CrossRef]

12. Carleton SC. Cardiac problems associated with electrical injury. Cardiol Clin 1995; 13: 263-6.
13. Varol E, Ozaydin M, Altinbas A, Dogan A. Low-tension electrical injury as a cause of atrial fibrillation: a case report. Tex Heart Inst J 2004; 31: 186-7.

14. Akkaş M, Hocagil H, Ay D, Erbil B, Kunt MM, Ozmen MM. Cardiac monitoring in patients with electrocution injury. Ulus Travma Acil Cerrahi Derg 2012; 18: 301-5. [CrossRef]

15. Arrowsmith J, Usgaocar RP, Dickson WA. Electrical injury and the frequency of cardiac complications. Burns 1997; 23: 576-8. [CrossRef]

16. Karadaş $S$, Gönüllü $H$, Oncü $M R$, Işık D, Canbaz Y. The effects on complications and myopathy of different voltages in electrical injuries. Ulus Travma Acil Cerrahi Derg 2011; 17: 349-53. [CrossRef]

17. Arnoldo B, Klein M, Gibran NS. Practice guidelines for the management of electrical injuries. J Burn Care Res 2006; 27: 439-47. [CrossRef]

18. Teodoreanu R, Popescu SA, Lascar I. Electrical injuries. Biological values measurements as a prediction factor of local evolution in electrocutions lesions. J Med Life 2014; 7: 226-36.

19. Yan GX, Antzelevitch C. Cellular basis for the normal T wave and the electrocardiographic manifestations of the long-QT syndrome. Circulation 1998; 98: 1928-36. [CrossRef]

20. Antzelevitch C, Shimizu W, Yan GX, Sicouri S. Cellular basis for QT dispersion. J Electrocardiol 1998; 30: 168-75. [CrossRef]

21. Topilski I, Rogowski O, Rosso R, Justo D, Copperman Y, Glikson M, et al. The morphology of the QT interval predicts torsade de pointes during acquired bradyarrhythmias. J Am Coll Cardiol 2007; 49: 320-8. [CrossRef]

22. Akilli NB, Akinci E, Akilli H, Dundar ZD, Koylu R, Polat M, et al. A new marker for myocardial injury in carbon monoxide poisoning: T peak-T end. AJEM 2013; 31: 1651-5. [CrossRef]

23. Mozos I, Serban C. The relation between QT interval and T-wave variables in hypertensive patients. J Pharm Bioallied Sci 2011; 3: 339-44. [CrossRef]

24. Lubinski A, Kornacewicz-Jach Z, Wnuk-Wojnar AM, Adamus J, Kempa M, Krolak T, et al. The terminal portion of the T wave: a new electrocardiographic marker of risk of ventricular arrhythmias. Pacing Clin Electrophysiol 2000; 23: 1957-9. [CrossRef]

25. Koumbourlis, Anastassios C. Electrical injuries from the Division of Critical Care. In: College of Physicians and Surgeons of Columbia University, Morgan Stanley Children's Hospital of New York Presbyterian. New York: Lippincott Williams Wilkins; 30, 11 2002; S424-S30.

26. Rai J, Jeschke MG, Barrow RE, Herndon DN. Electrical injuries: a 30-year review. J Trauma 1999; 46: 933-6. [CrossRef] 